\title{
Effects of 8-Week Strength Training on the Vertical Jump Performance of the Traceurs
}

\author{
Sinan Seyhan ${ }^{1, *}$ \\ ${ }^{1}$ Faculty of Sport Sciences, Celal Bayar University, Manisa, Turkey \\ *Correspondence: Faculty of Sport Sciences, Manisa Celal Bayar University, Halil Erdogan St. 45040 Manisa, \\ Turkey. Tel: 90-236-231-3002. E-mail: sinan.seyhan@cbu.edu.tr
}

Received: January 21, 2019

Accepted: March 5, 2019 Online Published: March 18, 2019

doi:10.5430/jct.v8n2p11

URL: https://doi.org/10.5430/jct.v8n2p11

\begin{abstract}
The parkour is a physical activity that contains special technique applications and requires a great number of jumps. The purpose of this study was to investigate the effects of 8-week strength training on the jump heights of the traceurs (parkour practitioners). A total of 12 traceurs, including 6 individuals as the control group and 6 individuals as the strength group, were included in the study. The control group was provided with parkour training sessions twice a week, and the other group provided with both strength and parkour training sessions twice a week. Each participant's vertical jumps were recorded with the high-speed camera in the validated My Jump 2 application. The mean age of the traceurs control group was $19 \pm .89$ years, $173.67 \pm 4.63 \mathrm{~cm}$, body mass $66.5 \pm 5.32 \mathrm{~kg}$; experimental group was $19.5 \pm 1.05$ years, $175.83 \pm 8.86 \mathrm{~cm}$, and body mass $67.67 \pm 7.20 \mathrm{~kg}$. Also according to the results, it can be said that a significant increase was observed in countermovement jump (CMJ) vertical jump heights $(\mathrm{p}=0.028)$ of the study group at the end of the 8-week strength trainings compared to the control group and that the strength training provided a positive contribution to vertical jump heights. On the other hand, there was no significant difference $(\mathrm{p}=0.075)$ in the control group. At the same time, the CMJ height values of the participants who performed strength training increased $4.97 \pm 0.09 \%$. Learning of the vertical jump heights, which is an important parameter for successful performance in traceurs, can enable the coaches and athletes to prepare a better training program.
\end{abstract}

Keywords: traceur, vertical jump, strength training

\section{Introduction}

The parkour, which spread from the back streets of France all over the world, can be defined as a physical activity that involves a wide range of movements, such as swinging, jumping, balancing, running in order to pass under and over any obstacle, and that requires some knowledge and skills when doing so. Athletes, called traceurs (parkour practitioners), have to overcome all of the determined obstacles with their body structures, flexibilities, all other physical qualities such as running and jumping. Traceurs complete the course by making movements that strain themselves physically with these individual features (Larsen, 2015; Grosprete \& Lepers, 2016). Parkour sport can be defined as the ability not only to move quickly in urban areas and in natural environments by using the physical qualities of the body, but also as the ability of traceurs to overcome the obstacles they encounter by combining their self with the structural features of the city (Thomson, 2008). The special movements that form the basis of the parkour sport are based on the disciplines of running and jumping in sports branches such as gymnastics and athletics. For this reason, it is possible for them to be successful by fulfilling certain requirements of gymnastics and athletics branches in order to overcome urban and natural obstacles without any material requirement (Grosprete, Ufland, \& Jecker, 2017).

When the literature is examined, unlike other sports branches, there are not many studies about this sport. As in every sports branch, it is known that the basic muscle strength of the lower extremities in the balanced and strong levels in the parkour sport is extremely important for optimal performance and prevention of the injuries. Hamstrings and Quadriceps muscle groups, which are the lower extremity muscle groups, play an important role in acceleration, deceleration, jumping, falling from height to ground and other physical activities (Willigenburg, McNally, \& Hewett, 2015; Zorba, et al., 2010). The quadriceps femoris, the single extensor muscle of the knee joint, plays an important 
role in the dynamic movements of the lower extremity. This muscle group stabilizes the knee joint by patella and patellar tendon. While the quadriceps muscle group plays an important role in jump, balance and ball strike movements, the hamstring muscle group prevents the formation of lower extremity injuries by maintaining the joint stabilization as of its position, apart from enabling the basic physical movements such as running and turns (Karsan, Yunceviz, \& Aydın, 1999).

It is known that in this newly developing sport branch, the muscle skills of traceurs interested in this sport improve thanks to the trainings and parkour applications and this situation significantly contributes to the their jumping skills as well. Thus, with parkour applications, traceurs provide better resistance to high eccentric load, and these trainings help to strengthen and develop musculoskeletal structures (Grospretre \& Romuald, 2016). In the literature, the Countermovement Jump Test (CMJ) is known as the most commonly used vertical jumping technique to determine not only heights but also the force and time curves for assessing the neuromuscular functions of athletes (McMahon, Suchomel, Lake, \& Comfort, 2018). Many studies showed that lower extremity strength levels of athletes have a positive relationship with the CMJ performance. CMJ was used as a reference to provide the development of muscles of the lower extremities and muscles of different types (Nuzzo, McBride, Cormie, \& McCaulley, 2008; Sheppard, Cronin, Gabbett, McGuigan, et al., 2008).

Traceurs need to jump as fast and as high as possible in order to overcome more challenging obstacles, so that each traceur's explosive power must be improved. Therefore, the aim of this study was to investigate the effects of 8-week strength training on jumping performance of the traceurs.

\section{Methods}

\subsection{Participant (Subject) Characteristics}

This study was carried out with twelve volunteer traceurs, 6 individuals as the experimental group and 6 individuals as the control group. Participants were informed about the purpose and method of the study before starting the study. The study included individuals who were older than 18 and were engaged in parkour sport for at least 2 years. Participants were randomly divided into two balanced groups. One group was provided with parkour training sessions, and the other group provided with both strength and parkour training sessions.

\subsection{Descriptive Data of the Athletes}

Height: In anatomical posture, with bare feet, joined heels, head in the frontal plane, overhead level touching the vertex point, while the subject is holding the breath, the heights of the athletes was measured with a stadiometer (Seca, Germany) that has a precision of $0.01 \mathrm{~m}$ and the values were recorded in $\mathrm{cm}$.

Body Weight: In anatomical posture, with bare feet and only shorts being worn, the body weights of the athletes were measured with a stadiometer (Seca, Germany) that has a precision of $0.01 \mathrm{~m}$ and the values were recorded in $\mathrm{kg}$.

The participants were applied a standard 10-minute warm-up consisting of running, lower extremity dynamic warm-up movements and vertical jumps. The participants were asked to jump up with maximum power after they kneel down rapidly in the normal upright position. Using the IPhone 7 mobile phone (Apple Inc USA), each participant's vertical jumps were recorded with the high-speed camera in the validated My Jump 2 application (Balsalobre-Fernandez, Glaister, \& Lockey, 2015). Each participant was asked to do vertical jumps 3 times as high as possible. At the end of each jump, a passive rest period of 2 minutes was given. In the video, the participants' take-offs and landings were determined. Then, the jump distance was calculated using the equation $\left(\mathrm{h}=\mathrm{t}^{2} \times 1.22625\right)$ which determines the jump height. The best results were considered in the evaluation (Bosco, Luhtanen, \& Komi, 1983).

The participants, who did strength training along with the parkour trainings, applied 4 sets of strength training exercises with 10 repetitions determined from ACSM two days a week, with a minimum of 72 hours between these days. In this exercise protocol, the movements of back squat, seated leg extension, seated leg curls, machine hip adductions, machine hip abductions, standing calf raises, back lat pulldowns, seated rows, bench press, incline bench press, biceps curls, triceps pushdowns, back press, back extension, and sit-ups were performed. The control group applied only two hours of parkour training for two days a week.

\subsection{Data Analysis}

Considering the kurtosis and skewness values, the data were found to be outside the range of $+1.5 /-1.5$. As the results of Kolmogorov-Smirnov test were taken into consideration when the number of data was low, it was decided to 
perform a nonparametric test.

The data obtained from the participants, descriptive features of participants, arithmetic means (X), standard deviations (SD) were analyzed and Wilcoxon test was performed for CMJ pre-test and post-test of the groups. At the same time, the normality of the data was also confirmed by Kolmogorov-Smirnov test. Significance level was determined as $5 \%(\mathrm{p}<0.05)$.

\section{Results}

The results of the data collected from 12 traceurs who participated in the study are presented in the tables below. The descriptive statistics of 12 traceurs who participated in the study are shown in Table 1.

Table 1. Descriptive Features of Participants

\begin{tabular}{lll}
\hline & Control Group Traceurs $(\mathrm{n}=6)$ & Experimental Group Traceurs $(\mathrm{n}=6)$ \\
\hline Age (years) & $19 \pm, 89$ & $19,5 \pm 1,05$ \\
Height $(\mathrm{cm})$ & $173,67 \pm 4,63$ & $175,83 \pm 8,86$ \\
Weight $(\mathrm{kg})$ & $66,5 \pm 5,32$ & $67,67 \pm 7,20$ \\
\hline
\end{tabular}

Kg: Kilogram, cm: Centimeter

The mean age of the traceurs control group was $19 \pm .89$ years, $173.67 \pm 4.63 \mathrm{~cm}$, body mass $66.5 \pm 5.32 \mathrm{~kg}$; experimental group was $19.5 \pm 1.05$ years, $175.83 \pm 8.86 \mathrm{~cm}$, and body mass $67.67 \pm 7.20 \mathrm{~kg}$.

Table 2. CMJ Height Values Before \& After Trainings of the Experimental Group

\begin{tabular}{lllll}
\hline Participants & \multicolumn{2}{c}{ Before Strength Training $(\mathrm{cm})$} & \multicolumn{2}{c}{ After Strength Training $(\mathrm{cm})$} \\
\cline { 2 - 5 } & Mean & sd & Mean & sd \\
\hline Traceur 1 & 47,90 & 0,07 & 50,23 & 0,12 \\
Traceur 2 & 43,16 & 0,42 & 45,18 & 0,09 \\
Traceur 3 & 49,76 & 0,49 & 51,35 & 0,03 \\
Traceur 4 & 41,87 & 0,20 & 44,63 & 0,05 \\
Traceur 5 & 49,94 & 0,14 & 52,45 & 0,07 \\
Traceur 6 & 47,33 & 0,05 & 50,01 & 0,08 \\
Group Mean & 46,66 & 0,20 & $48,98^{*}$ & 0,02 \\
\hline
\end{tabular}

*Significant difference to pre-training $(\mathrm{p}<0.05)$.

According to the data obtained from the participants, Wilcoxon test was applied to determine the difference between the tests before and after weight trainings. According to the data obtained, a significant difference $(\mathrm{p}=0.028)$ was found in CMJ vertical jump heights $(\mathrm{p}<0.05)$. CMJ height values of the participants who peformed strength trainings increased by $4.97 \pm 0.09 \%$ on average (Table 2). According to these results, it can be said that weight training has a positive effect on the participants.

Table 3. CMJ Height Values Before \& After Trainings of the Control Group

\begin{tabular}{llllc}
\hline Participants & \multicolumn{2}{c}{ Before Strength Training $(\mathrm{cm})$} & \multicolumn{2}{c}{ After Strength Training $(\mathrm{cm})$} \\
\cline { 2 - 5 } & Mean & sd & Mean & sd \\
\hline Traceur 1 & 59,44 & 0,11 & 60,10 & 0,02 \\
Traceur 2 & 44,26 & 0,14 & 44,53 & 0,03 \\
Traceur 3 & 43,45 & 0,09 & 43,80 & 0,03 \\
Traceur 4 & 43,70 & 0,35 & 43,46 & 0,76 \\
Traceur 5 & 47,25 & 0,14 & 47,27 & 0,23 \\
Traceur 6 & 46,59 & 0,27 & 46,88 & 0,05 \\
Group Mean & 47,45 & 0,13 & 47,67 & 0,15 \\
\hline
\end{tabular}

$*$ Significant difference to pre-training $(\mathrm{p}<0.05)$. 
According to Table 3 , there was no significant difference $(p=0.075)$ between CMJ height values of the control group before and after trainings $(\mathrm{p}<0.05)$.

\section{Discussion}

The hypothesis of this study is that 8-week strength training will improve the explosive powers of the traceurs and have a positive effect on their jumping performances. At the end of the 8-week strength trainings, an increase was observed in the vertical jump heights of the experimental group and the strength training provided a positive contribution to the vertical jumping heights.

It is known that vertical jump height is the most important parameter in determining the lower extremity explosive performance of athletes. This jumping ability in athletes also brings physical success (Buchheit \& Spencer, 2010; de Villarreal, Izquierdo, \& Gonzalez-Badillo, 2011). The importance of strength training to increase the jumping performance of athletes is known. There are many statements in the literature about the definition of strength. The strength training is closely related to the feature of the internal force to be improved. Increasing the size of the muscle fibers in the muscles, increasing the number of muscle fibers, thus increasing the muscle contraction velocity and the development of nerve-muscle coordination are among the targets of a suitable strength training (Fox, Bowers \& Fos, 1988). As in some sports branches, the lower extremity muscles, which require explosive and maximal forces in the movements such as jump, sudden turn, fall and take-off, should be developed with proper strength trainings (Reilly, 1979). Many devices and methods were developed to measure this feature, which is so important for performance, in a reliable and valid manner in the literature. It was shown that My Jump smartphone application, which was specially developed can help strength and conditioning coaches who want to determine the vertical jumping ability in a valid and economical way and can be purchased from the Apple Store (Apple Inc., USA), can easily and reliably measure the vertical jump height. In this study, the use of this application provided convenience in terms of costs and usefulness (Turgut, Coban, \& Gelen, 2018; Bosco, Luhtanen, \& Komi, 1983).

According to the results obtained in this study, it was determined that the mean value of CMJ heights of the experimental group that performed the weight trainings increased at the end of 8 weeks compared to the initial measurement values $\left(46.66 \mathrm{~cm}<48.98 \mathrm{~cm}^{*}\right)$. At the same time, a significant increase was observed in CMJ vertical jumping heights of the group that performed 8 -week strength trainings $(\mathrm{p}=0.028)$ when compared to the control group and strength trainings provided a positive contribution to vertical jumping heights $(\mathrm{p}<0.05)$. At the same time, CMJ height values of the participants who performed strength trainings increased by $4.97 \pm 0.09 \%$. According to these data, it was observed that there was no significant difference between CMJ height values of the control group $(\mathrm{p}=0.05)$ by applying the traditional parkour training method, meaning that muscle development did not affect the jump heights $(\mathrm{p}<0.05)$. In contrast, the development of lower extremity muscles, which is a determinant feature of the performance of the other experimental group, is shown to provide better jump results. When the literature is reviewed, there are very few studies investigating the effect of strength training on parkour performance. In a study, it was reported that strength trainings provide neuromuscular advantages to the performances of athletes compared to plyometric trainings in order to increase the vertical jump height (De Villarreal, Requena, \& Newton, 2017; Jenkins, Miramonti, Hill, et al., 2017; Stojanovic, Ristic, McMaster, \& Milanovic 2017). In a similar study, it was observed that a significant increase was observed in the jump heights of the 20 parkour athletes using the 8-week strength training method (Rocha, Silva, Oliveira, Szmuchrowski, et al., 2017). In order to increase the number of such studies, other weight training methods should be applied to the parkour sport and the number of relevant tests and available studies should be increased.

\section{Conclusion}

According to the results, it can be said that a significant increase was observed in countermovement jump (CMJ) vertical jump heights $(\mathrm{p}=0.028)$ of the study group at the end of the 8-week strength trainings compared to the control group and that the strength training provided a positive contribution to vertical jump heights. On the other hand, there was no significant difference $(\mathrm{p}=0.075)$ in the control group. At the same time, the CMJ height values of the participants who performed strength training increased $4.97 \pm 0.09 \%$. In conclusion, specific tests to the parkour sport and other strength training protocols should be developed. In sports branches where jumping performances are important, it is seen that strength training is very important for athletes' performances besides normal training programs. Also it is thought that learning and understanding of the vertical jump height, which is an important parameter for successful performance in traceurs, by coaches and athletes, can contribute to the preparation of better training programs and exercise programs. 


\section{References}

Balsalobre-Fernandez, C., Glaister, M., \& Lockey, R.A. (2015). The Validity and Reliability of an İphone App for Measuring Vertical Jump Performance. J. Sports Sci., https://doi.org/10.1080/02640414.2014.996184

Bosco, C., Luhtanen, P., \& Komi, P. V. (1983). A Simple Method for Measurement of Mechanical Power İn Jumping. European Journal of Applied Physiology and Occupational Physiology, 50(2), 273-282. https://doi.org/10.1007/BF00422166

Buchheit, M., \& Spencer, M. A. S. (2010). Reliability, Usefulness, And Validity of A Repeated Sprint and Jump Ability Test. Int J Sports Physiol Perform, 5(1), 3-17. https://doi.org/10.1123/ijspp.5.1.3.

De Villarreal E. S. S., Requena, B., \& Newton, R. U. (2017). Does Plyometric Training İmprove Strength Performance? A Meta-Analysis. J. Sci. Med. Sport., 13(5), 513-522. https://doi.org/10.1016/j.jsams.2009.08.005

De Villarreal, E. S. S., Izquierdo, M., \& Gonzalez-Badillo, J. J. (2011). Enhancing Jump Performance After Combined Vs. Maximal Power, Heavy-Resistance, And Plyometric Training Alone. The Journal of Strength \& Conditioning Research, 25(12), 3274-3281. https://doi.org/10.1519/JSC.0b013e3182163085

Fox, E. L., Bowers, R. W., \& Fos, M. I. (1988). The Physisiological Basis of Physical Education and Atletics. Saunders Collage Publishing, 4.

Grosprete S., Ufland P., \& Jecker D. (2017). The Adaptation to Standing Long Jump Distance İn Parkour İs Performed By the Modulation of Specific Variables Prior and During Take-Off. Mov Sport Sci/ Sci Mot., $27-37$. https://doi.org/10.1051/sm/2017022.

Grospretre, S., \& Lepers, R. (2016). Performance Characteristics Of Parkour Practitioners: Who Are The Traceurs? European Journal of Sport Science, 16(5), 526-535. http://dx.doi.org/10.1080/17461391.2015.1060263

Jenkins, N. D. M., Miramonti, A. A., Hill, E. C., Smith, C. M., Cochrane-Snyman, K. C., Housh, T. J., \& Cramer, J. T. (2017). Greater Neural Adaptation Following High Vs Low Load Resistance Training. Frontiers Physiol., 8, 331. https://doi.org/10.3389/fphys.2017.00331.

Karsan, O., Yünceviz R., \& Aydın, S. (1999). Quadriceps (Q) Angle Values in Physical Education and Sports Students, Journal of Dynamic Sports Sciences. Mugla, 1, 45-52.

Larsen, S. H. (2015). Parkour. The Institutionalization of a New Movement Culture in Denmark. PhD thesis, University of Southern. Denmark.

McMahon, J. J., Suchomel, T. J., Lake J., \& Comfort P. (2018). Understanding the Key Phases of the Countermovement Jump Force-Time Curve. Strength and Conditioning Journal, 40(4), 96-106. http://dx.doi.org/10.1519/SSC.0000000000000375.

Nuzzo, J. L., McBride, J. M., Cormie, P., \& McCaulley, G. O. (2008). Relationship between Countermovement Jump Performance and Multijoint İsometric and Dynamic Tests of Strength. Journal of Strength \& Conditioning Research, 22, 699-707. https://doi.org/10.1519/JSC.0b013e31816d5eda

Reilly, T. (1979). What Research Tells The Coach About Soccer, American Alliance for Health, Physical Education, Recreation and Dance. Washington DC., 1-13.

Rocha, A. J., Silva, D. A. R., Oliveira, P. M., Szmuchrowski, A. L., Couto, P. B., \& Drummond, M. M. (2017). Chronic Effect of Strength Training on Vertical Jump Performance in Parkour Practitioners. Archıves of Budo Sclence of Martıal Arts and Extreme Sports, 13, 173-178.

Sheppard, J. M., Cronin, J. B., Gabbett, T. J., McGuigan, M. R., Etxebarria, N., \& Newton, R. U. (2008). Relative Importance of Strength, Power, and Anthropometric Measures to Jump Performance of Elite Volleyball Players. Journal of Strength \& Conditioning Research, 22, 758-765. https://doi.org/10.1519/JSC.0b013e31816a8440.

Stojanovic E., Ristic V., McMaster, D. T., \& Milanovic, Z. (2017). Effect of Plyometric Training on Vertical Jump Performance in Female Athletes: A Systematic Review and Meta-Analysis. Sport Med., 47(5), 975-986. https://doi.org/10.1007/s40279-016-0634-6

Thomson, D. (2008). Jump City. Parkour and the Traces. South Atlantic Quarterly, 107, $251-263$. https://doi.org/10.1215/00382876-2007-065

Turgut, A., Çoban, Ö. G., \& Gelen, E. (2018). Can Smart Phone Application Be Used in Determining Vertical Jump Performance? International Journal of Sports Exercise \& Training Sciences, 4(2), 79-83. 
https://doi.org/10.18826/useeabd.437153

Willigenburg, N. W., McNally, M. P., \& Hewett, T. E. (2015). Quadriceps and Hamstrings Strength in Athletes. In: Reading CC, Brochers JR, (Eds.), Hamstrings and Quadriceps Injuries in Athletes: A Clinical Guide. New York, Springer Science+Business Media. https://doi.org/10.1007/978-1-4899-7510-2_2

Zorba E., Özkan A., Akyüz M., Harmancı H., Taş M., \& Şenel Ö. (2010). The Relationship of Leg Volume and Leg Mass with Anaerobic Performance and Knee Strength in Wrestlers. International Journal of Human Sciences, $7(1), 83-96$. 